\title{
Internationally Comparable Indicators for Children of Immigrants
}

\author{
Donald J. Hernandez
}

Accepted: 3 May 2010 / Published online: 1 September 2010

(C) Springer Science+Business Media B.V. 2010

The number and diversity of immigrants to affluent countries has risen greatly during recent decades, with low and middle income countries becoming increasingly prominent in the mix of immigrant origins. Immigrants often are in the family building stage of life, bringing one or more children along to the settlement country and bearing additional children after they arrive. As a consequence, although considerable public attention, and often controversy, has focused on the rising share of adults in affluent countries who are immigrants, even larger is the share of all children who are children of immigrants. Yet not until 2009 did basic, internationally comparable indicators become available to measure the number of children in immigrant families living in a range of affluent countries, and to assess their family and socioeconomic circumstances compared to children in native-born families. The articles in this special edition of Child Indicators Research present an overview of these comparative results, as well as more in depth analyses for six countries.

Australia and the United States have long been recognized as settled mainly through mass migrations, and these countries continue to receive many immigrants. Results from the most recent census in Australia indicate that one-third (33\%) of children have at least one immigrant parent, and recent results for the United States indicate that nearly one-fourth (24\%) are children of immigrants. The proportions also are very high, however, in other countries included in the recent comparative study, at four-in-ten for Switzerland (39\%), one-in-four for Germany (26\%), one-infive for Netherlands (22\%), and one-in-six in France (17\%) and the United Kingdom $(16 \%)$. Even in Italy, which historically experienced little immigration, one-in-ten children (10\%) live with an immigrant parent as of the 2001 census, and an article in this volume indicates that this proportion is likely to have grown substantially since that time (Mencarini 2010).

Recent immigration differs from historic trends in a critically important way. European countries were the primary source of early mass migrations. But in recent

D. J. Hernandez $(\triangle)$

Department of Sociology, Hunter College, 1622 Hunter West, 695 Park Avenue, New York, NY 10065, USA

e-mail: Donald.Hernandez@hunter.cuny.edu 
decades many immigrants are from low and middle income countries, often in Africa, Asia, Latin America and the Caribbean, or Oceania, and these immigrants and their children may differ in physical appearance, language, religion, and culture from the non-immigrant population, making them subject to racial or ethnic discrimination in school or the labor market. Among the countries in the new comparative study, between one-third and one-half of children in immigrant families in Australia have origins in low and middle income countries, and this proportion rises to between one-half and eight-tenths in France, Italy, the Netherlands, Switzerland, the United Kingdom, and the United States. Among the eight study countries the proportion is as small as one-in-ten only in Germany.

The changing sources of immigration raise new issues regarding how best to assure the integration and inclusion of immigrants and their children. To address these issues, it is essential to have statistical indicators for children and their families that provide basic information not only about their numbers, but also their origins, their family composition, and their educational, economic, and housing conditions, compared to children in the native-born families of settlement countries. The recent study, which provides the primary information for this special edition, is the first to develop such internationally comparable child indicators for a range of affluent countries. This study was commissioned by the UNICEF Innocenti Research Centre (IRC) in Florence, Italy, with the goal of providing baseline information to fill the enormous knowledge gap, as a foundation for discussion of social policies relevant to children in immigrant families.

The study was conducted by experts in eight countries who were convened by IRC. Insofar as different approaches to measuring important concepts exist in national statistical systems, these scholars collaborated to develop a common set of measures that would provide a valid basis for international comparisons. Because only the data for the United States have been previously used to describe the circumstances of children in immigrant families, it was necessary to reorganize data sets for each of the other seven countries with children as the unit of analysis by creating an individual record for each child, and attaching relevant data for parents and families to each child's record. (For a detailed analysis for the United States, see Hernandez et al. (2008)). It also was necessary to recode variables to conform to the internationally comparable indicators developed by the expert group. To calculate results, scholars in each country worked with data from their own country, often in collaboration with their national statistical office.

Children in immigrant families in many affluent countries will become an important force in the economies and political systems of these countries during the coming years, and they will provide essential resources to support the rapidly aging non-immigrant populations of these countries. To provide a strong foundation for policies which assure the integration and inclusion of rapidly growing populations of children in immigrant families, additional affluent nations would benefit from replicating with their own data the new child indicators developed for the UNICEF project and presented in the articles of this volume. It also will be critical to conduct repeated analyses with new data over time to regularly monitor the changing situation of children in immigrant and native-born families.

Without expanded and repeated studies, affluent nations with large immigrant populations will not have basic, up-to-date information necessary to develop 
effective policies which will promote the integration and well-being of children, and which will assure that they are in a position to effectively contribute to the society and broader economy of the countries where their parents have settled. The articles in this volume seek to contribute to the goal of developing such policies by presenting and interpreting new child indicator results in light of relevant literature on immigration and well-being for a set of affluent countries which are home to nearly $40 \%$ of all international immigrants.

\section{Reference}

Hernandez, D. J., Denton, N. A., \& Macartney, S. E. (2008). Children in immigrant families: looking to America's future. Social Policy Report, Volume 22, Number 3, Ann Arbor, MI: Society for Research in Child Development. Retrieved 10 July 2008 from http://www.srcd.org/index.php? option $=$ com content $\&$ task $=$ view $\&$ id $=232 \&$ Itemid $=1$.

Mencarini, L. (2010). A portrait of children in immigrant families in Italy. Child Indicators Research. doi:10.1007/s12187-010-9070-6. 